\title{
A revenge problem without the concept of truth
}

Article

Accepted Version

Pinder, M. (2015) A revenge problem without the concept of truth. Thought: A Journal of Philosophy, 4 (3). pp. 151-161. ISSN 2161-2234 doi: https://doi.org/10.1002/tht3.168 Available at https://centaur.reading.ac.uk/40849/

It is advisable to refer to the publisher's version if you intend to cite from the work. See Guidance on citing.

To link to this article DOI: http://dx.doi.org/10.1002/tht3.168

Publisher: Wiley

All outputs in CentAUR are protected by Intellectual Property Rights law, including copyright law. Copyright and IPR is retained by the creators or other copyright holders. Terms and conditions for use of this material are defined in the End User Agreement.

\section{www.reading.ac.uk/centaur}

\section{CentAUR}

Central Archive at the University of Reading

Reading's research outputs online 


\title{
A revenge problem without the concept of truth
}

\author{
Mark Pinder \\ Department of Philosophy, University of Reading
}

This paper is forthcoming in Thought: A Journal of Philosophy. Please do not cite this version.

\begin{abstract}
The vast majority of putative solutions to the liar paradox face the infamous revenge problem. In recent work, however, Kevin Scharp has extensively developed an exciting and highly novel 'inconsistency approach' to the paradox that, he claims, does not face revenge. If Scharp is right, then this represents a significant step forward in our attempts to solve the liar paradox. However, in this paper, I raise a revenge problem that faces Scharp's inconsistency approach.
\end{abstract}

\section{Introduction}

The vast majority of putative solutions to the liar paradox face the infamous revenge problem. This revenge problem is often thought to be a mere reoccurrence of the initial paradox: a putative solution that faces revenge, so goes the thought, has not successfully solved the liar paradox at all. In recent work, Kevin Scharp has extensively developed an exciting and highly novel 'inconsistency approach' to solving the paradox. Building upon the intuitive idea that the concept of truth is the source of the liar paradox, Scharp radically proposes to replace the concept of truth for theoretical purposes. ${ }^{1}$ By removing the source of the liar paradox from our theorising, Scharp claims that we can avoid facing any kind of revenge problem.

If Scharp is right, then his inconsistency approach represents a significant step forward in our attempts to solve the liar paradox: it goes some way towards vindicating the intuitive idea that the concept of truth is the issue underlying the liar paradox and subsequent revenge problems; and it

\footnotetext{
${ }^{1}$ See e.g. Scharp 2013a,b, 2014.
} 
provides a clear strategy for resolving the issue by removing and replacing the concept of truth from our conceptual scheme.

Contrary to Scharp, however, I argue in the present paper that his inconsistency approach does face a revenge problem. In §2 I outline the relevant background material, before raising the problem in $\S 3$, replying to potential objections in $§ 4$, and concluding in $\S 5$.

\section{Background}

\subsection{The liar paradox and revenge problems}

The liar paradox arises when one reasons about the truth value of a liar sentence such as $\lambda$ :

$\sim \mathrm{T}(\lambda)$

where " $\mathrm{T}(\cdot)$ " is the truth predicate and " " is negation. Consider the following highly intuitive principles about truth:

(T-in) $\quad \mathrm{p} \rightarrow \mathrm{T}([\mathrm{p}\rceil)$

(T-out) $\mathrm{T}([\mathrm{p}]) \rightarrow \mathrm{p}$

where "p" is a sentential variable, and " $[p]$ " is a name of the sentence replacing " $p$ ". Using these principles, and given that $\lambda=[\sim T(\lambda)]$, it is straightforward to classically derive:

$(\perp) \quad \mathrm{T}(\lambda) \wedge \sim \mathrm{T}(\lambda)$.

This, however, is a contradiction. 
A vast number of putative solutions to the liar paradox have been put forward, the vast majority of which face some kind of revenge problem. ${ }^{2}$ As noted, the revenge problem is often taken to be a mere reoccurrence of the initial paradox; thus Beall tells us that the revenge problem "is not so much a separate phenomenon from the Liar as it is what makes the Liar phenomenon challenging" (2007: 4). The revenge problem arises as, in order to avoid the paradox, putative solutions typically impose expressive constraints on the object language - constraints to which natural languages appear not to be subject. If we attempt to apply the putative solution to a liar-like sentence constructed from the additional resources available to a natural language, it is typically possible, using parallel reasoning to that employed in the original liar paradox, to once again derive a contradiction.

Suppose, for example, that one attempts to solve the paradox by denying the law of the excluded middle: perhaps the liar sentence neither falls under "true" nor "not true", blocking the derivation of $(\perp) .^{3}$ The problem is that, plausibly, natural languages contain Boolean negation

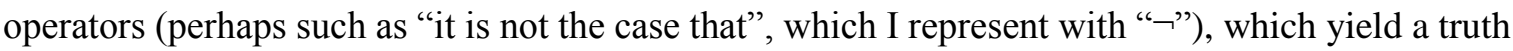
when applied to a subject-predicate sentence whose subject does not fall under its predicate. By consideration of a liar sentence that makes use of such an operator, such as $\lambda^{\dagger}$ :

$\neg \mathrm{T}\left(\lambda^{\dagger}\right)$

one can use parallel reasoning to that employed in the original liar paradox to re-establish a contradiction. This casts doubt on the adequacy of the putative solution of the liar paradox. ${ }^{4}$

There are various possible responses to revenge problems. ${ }^{5}$ In particular, one might simply deny that the object language has the relevant expressive resources required to generate revenge. But,

\footnotetext{
${ }^{2}$ Kevin Scharp calls the version of revenge I introduce here "the inconsistency problem"; he also discusses a version called "the self-refutation problem", which occurs when a putative solution to the paradoxes deems itself untrue, that will not concern us here. See Scharp 2013a: 99-100.

${ }^{3}$ See e.g. Kripke 1975.

${ }^{4}$ See e.g. Beall 2007: 11-12.

${ }^{5}$ In addition to the line of response mentioned in the text, see Beall 2007: 8-11; and Shapiro 2011.
} 
insofar as one is attempting to solve the liar paradox as it arises in natural language, such a response may seem somewhat ad hoc: for example, the claim that the object language is subject to expressive constraints is not typically accompanied by linguistic evidence that natural languages are subject to those constraints. Regardless, we put aside such responses in what follows. We are concerned with the possibility of an effective solution to the liar paradox that genuinely does not face any revenge problems whatsoever.

\subsection{Scharp's inconsistency approach}

Scharp (2013a,b, 2014) develops what he calls an inconsistency approach to the liar paradox (and to the paradoxes of truth more generally). ${ }^{6}$ There are three central components to his approach. ${ }^{7}$

- A diagnostic theory. Scharp claims that the liar paradox arises because the concept of truth is, in a technical sense to be made clear, inconsistent.

- A prescriptive theory. Scharp argues that we should, for theoretical purposes, replace the concept of truth with two technical concepts, called ascending truth and descending truth.

- A descriptive theory. Scharp uses the replacement concepts (of ascending and descending truth) to provide a consistent semantics for the natural language term "true".

Let us take these in turn.

According to Scharp's diagnostic theory, the liar paradox arises because the concept of truth is inconsistent. Here, concepts are characterised as being constituted in some sense by principles; and a concept is inconsistent if its constitutive principles are jointly inconsistent (with the facts). The concept of truth is deemed inconsistent as, for Scharp, each instance of (T-in) and (T-out) is taken to

\footnotetext{
${ }^{6}$ Henceforth, I leave the parenthesised extension to other paradoxes implicit.

${ }^{7}$ See Scharp 2013b: 435. Some may prefer to think of only the diagnostic theory as Scharp's 'inconsistency approach'.

However, Scharp characterises both prescriptive and descriptive theories as "major component[s]" of "an adequate inconsistency approach" (2013b: 461). I follow Scharp's use of “inconsistency approach" throughout this paper. For the sake of clarity, I note that the revenge problem I raise below does not affect Scharp's diagnostic theory, but principally targets Scharp's prescriptive and descriptive theories.
} 
be constitutive of the concept of truth, despite together being jointly inconsistent (with the fact that $\lambda$ is $[\sim T(\lambda)])$.

According to Scharp's prescriptive theory, we should replace the concept of truth, for certain theoretical purposes, with a pair of consistent concepts: ascending truth and descending truth. Scharp provides a full formal theory for these concepts, ADT. Below, I will sketch a fragment of ADT. ${ }^{8}$

Before proceeding, I note that ADT does not require a distinction between object language and metalanguage. As such, Scharp presents ADT without any such distinction. However, for present purposes, it will be useful to reinstate the distinction (albeit acknowledging that the object language may be the metalanguage). In what follows, then: "p $p_{o}$ " is to be understood (schematically) as a sentence of the object language, and "p" its translation in the metalanguage; " $\left[\mathrm{p}_{\mathrm{o}}\right]$ " is a metalinguistic name of an object language sentence; "Not" is a negation operator in the object language; and " " and " $\rightarrow$ " are the negation operator and material conditional in the metalanguage. " $\mathrm{A}(\cdot)$ " and " $\mathrm{D}(\cdot)$ " are predicates of the metalanguage expressing ascending truth and descending truth, respectively. To be explicit, the object language may also contain ascending and descending truth predicates.

Now, ascending truth and descending truth are similar to the ordinary concept of truth, each satisfying analogues of some (but not all) of the principles intuitively satisfied by truth. For example, ascending truth satisfies an unrestricted analogue of (T-in), descending truth satisfies an unrestricted analogue of (T-out), but not vice versa. Schematically, we thus have:
(A) $\quad \mathrm{p} \rightarrow \mathrm{A}\left(\left[\mathrm{p}_{\mathrm{o}}\right]\right)$
(D) $\quad \mathrm{D}\left(\left[\mathrm{p}_{\mathrm{o}}\right]\right) \rightarrow \mathrm{p}$.

Neither ascending truth nor descending truth satisfies an unrestricted analogue of $\left[\mathrm{T}\left(\left[\mathrm{p}_{\mathrm{o}}\right]\right) \leftrightarrow \sim \mathrm{T}\left(\left[\right.\right.\right.$ Not: $\left.\left.\left.\mathrm{p}_{\mathrm{o}}\right]\right)\right]$, but there is an unrestricted mixed analogue:

$$
\mathrm{D}\left(\left[\mathrm{p}_{\mathrm{o}}\right\rceil\right) \leftrightarrow \sim \mathrm{A}\left(\left[\text { Not: } \mathrm{p}_{\mathrm{o}}\right\rceil\right)
$$

\footnotetext{
${ }^{8}$ For details, see in particular Scharp 2013a: ch.6.
} 
We will use (A), (D) and (M) below. In addition, we will use (S):

$$
\sim \mathrm{A}\left(\left\lceil\mathrm{p}_{\mathrm{o}}\right\rceil\right) \rightarrow \sim \mathrm{D}\left(\left\lceil\mathrm{p}_{\mathrm{o}}\right\rceil\right)
$$

which is a corollary of (A) and (D).

Scharp's descriptive theory is a semantics for our ordinary word "true". In particular, Scharp develops a variant of truth-conditional semantics that does not employ the supposedly inconsistent concept of truth; rather, it employs the concepts of ascending and descending truth. ${ }^{9}$ We will make do with a substantially simplified version.

Truth-conditional semantic theories assign truth conditions to sentences at indexes, where an index is, say, an ordered tuple $\langle w, t\rangle$ with "w" a world-variable and " $t$ " a time-variable. As Scharp replaces the concept of truth with two concepts, however, his semantic theory assigns two conditions to sentences at indexes: an ascending truth condition and a descending truth condition. Thus, for each sentence of the object language, we obtain two theorems:

$$
\begin{aligned}
& \mathrm{A}_{\langle\mathrm{w}, \mathrm{t}\rangle}\left(\left[\mathrm{p}_{\mathrm{o}}\right\rceil\right) \leftrightarrow \mathrm{p}_{1} \\
& \mathrm{D}_{\langle\mathrm{w}, \mathrm{t}\rangle}\left(\left\lceil\mathrm{p}_{\mathrm{o}}\right\rceil\right) \leftrightarrow \mathrm{p}_{2}
\end{aligned}
$$

where " $\mathrm{p}_{1}$ " and " $\mathrm{p}_{2}$ " are to be replaced by a statement of the conditions under which $\left\lceil\mathrm{p}_{\mathrm{o}}\right\rceil$ is ascending and descending true respectively.

Scharp gives an assessment-sensitive semantics for "true". The idea is that, at each context of assessment, an alethic standard may be in force. There are two possible alethic standards: SA and SD. If SA is in force, then a use of "true" is interpreted as having the set of ascending truths as its extension. If SD is in force, then a use of "true" is interpreted as having the set of descending truths as its extension. I shall represent this here by adding a third parameter to the index in the ascending and

\footnotetext{
${ }^{9}$ See in particular Scharp 2013a: ch.9.
} 
descending truth conditions. Thus, depending on one's context of assessment, one might obtain for an object language sentence of the form [true $(\mathrm{x})]$ one of two pairs of theorems. From SA, one obtains the ascending/descending truth conditions $(1 \mathrm{a}, \mathrm{b})$; and from $\mathrm{SD}$, one obtains the ascending/descending truth conditions $(2 \mathrm{a}, \mathrm{b}) .{ }^{10}$
(a) $\quad \mathrm{A}_{\langle\mathrm{w}, \mathrm{t}, \mathrm{SA}\rangle}([\operatorname{true}(\mathrm{x})]) \leftrightarrow \mathrm{A}_{\langle\mathrm{w}, \mathrm{t}, \mathrm{SA}\rangle}([\mathrm{A}(\mathrm{x})])$
(b) $\quad \mathrm{D}_{\langle\mathrm{w}, \mathrm{t}, \mathrm{SA}\rangle}([\operatorname{true}(\mathrm{x})]) \leftrightarrow \mathrm{D}_{\langle\mathrm{w}, \mathrm{t}, \mathrm{SA}\rangle}([\mathrm{A}(\mathrm{x})])$

(2)
(a) $\quad \mathrm{A}_{\langle\mathrm{w}, \mathrm{t}, \mathrm{SD}\rangle}([\operatorname{true}(\mathrm{x})]) \leftrightarrow \mathrm{A}_{\langle\mathrm{w}, \mathrm{t}, \mathrm{SD}\rangle}([\mathrm{D}(\mathrm{x})])$
(b) $\quad \mathrm{D}_{\langle\mathrm{w}, \mathrm{t}, \mathrm{SD}\rangle}([\operatorname{true}(\mathrm{x})]) \leftrightarrow \mathrm{D}_{\langle\mathrm{w}, \mathrm{t}, \mathrm{SD}\rangle}([\mathrm{D}(\mathrm{x})])$

The semantic theory contains axioms that govern compositionality in the object language in the usual way. ${ }^{11}$ We will use a simplified set of axioms for negation. ${ }^{12}$ Where "p ${ }_{o}$ " is a sentence of the object language, and "Not" is the negation operator in the object language, we have:
$\left(\mathrm{N}_{\mathrm{A}}\right) \quad \mathrm{A}_{\langle\mathrm{w}, \mathrm{t,s}\rangle}\left(\left[\mathrm{Not}: \mathrm{p}_{\mathrm{o}}\right]\right) \leftrightarrow \sim \mathrm{A}_{\langle\mathrm{w}, \mathrm{t}, \mathrm{s}}\left(\left[\mathrm{p}_{\mathrm{o}}\right]\right)$
$\left(\mathrm{N}_{\mathrm{D}}\right)$
$\mathrm{D}_{\langle\mathrm{w}, \mathrm{t}, \mathrm{s}\rangle}\left(\left[\right.\right.$ Not: $\left.\left.\mathrm{p}_{\mathrm{o}}\right]\right) \leftrightarrow \sim \mathrm{D}_{\langle\mathrm{w}, \mathrm{ts}\rangle}\left(\left[\mathrm{p}_{\mathrm{o}}\right\rceil\right)$

\footnotetext{
${ }^{10}$ For simplicity, I assume (here and below) that the object language has been extended to include its own ascending and descending truth predicates. To be clear, however, this assumption is not essential. See Scharp 2013a: 249; 2013b: 479-480.

${ }^{11}$ See Scharp 2013a: 248; 2013b: 478.

${ }^{12}$ To simplify the discussion, I here bypass the (otherwise important) distinction between a semantic theory and a postsemantic theory. Roughly, the semantic theory provides a definition of truth-in-a-model such that: $\left\lceil\right.$ Not: $\left.p_{0}\right\rceil$ is true-in-M at point of evaluation $\langle\mathrm{w}, \mathrm{t}, \mathrm{v}, \mathrm{s}\rangle$ iff $\left\lceil\mathrm{p}_{\mathrm{o}}\right\rceil$ is not true-in-M at point of evaluation $\langle\mathrm{w}, \mathrm{t}, \mathrm{v}, \mathrm{s}\rangle(2013 \mathrm{a}: 248)$. Here, w,t,s are as before, but " $\mathrm{v}$ " is an alethic value parameter, which can take either ascending truth or descending truth as its value. Then, roughly, the postsemantic theory tells us that a sentence is ascending/descending true (in a context of utterance, $u$, from a context of assessment, a) iff that sentence is true-in-M at the point of evaluation in which: w,t are the world and time of $u, s$ is the alethic standard of a, and $\mathrm{v}$ is ascending/descending truth (2013a: 259). Combining these aspects of Scharp's semantics: $\left\lceil\right.$ Not: $\left.\mathrm{p}_{\mathrm{o}}\right\rceil$ is ascending/descending true (in $\mathrm{u}$ from a) iff $\left\lceil\right.$ Not: $\left.\mathrm{p}_{\mathrm{o}}\right\rceil$ is true-in-M at the relevant point of evaluation iff $\left\lceil\mathrm{p}_{\mathrm{o}}\right\rceil$ is not true-in-M at that point of evaluation iff $\left\lceil\mathrm{p}_{\mathrm{o}}\right\rceil$ is not ascending/descending true (in $\mathrm{u}$ from a). Hence $\left(\mathrm{N}_{\mathrm{A}}\right)$ and $\left(\mathrm{N}_{\mathrm{D}}\right)$.
} 
if $\mathrm{w}$ and $\mathrm{t}$ are the world and time of a context of utterance, and $\mathrm{s}$ is the alethic standard of a context of assessment.

By adopting his inconsistency approach, Scharp claims that

one has a satisfying explanation of why the aletheic paradoxes occur, why we are taken in by their reasoning, and why other theories of truth face revenge paradoxes (Scharp 2013a: 116).

The explanation is ultimately that the concept of truth is inconsistent, and that the other theories of truth in question make essential use of that concept. By replacing truth, one might thus seriously hope to avoid any revenge problem whatsoever. It is in this spirit that, after considering various unsuccessful attempts to generate a revenge problem, Scharp claims that "there is no way of generating a revenge paradox for this approach" (2014: 642). In the next section, however, I raise a revenge problem facing Scharp's inconsistency approach, and its prescriptive and descriptive theories in particular.

\section{Revenge}

Scharp provides an assessment-sensitive treatment of "true". As such, one might ask of a particular sentence that contains "true" whether it is (ascending/descending) true from some context of assessment, irrespective of one's own context of assessment. It is natural to do this by introducing a new predicate, "true-from-some-context", such that: "x is true-from-some-context" is ascending true (whichever alethic standard is force) just in case there is an alethic standard that would render " $\mathrm{x}$ is true" ascending true; and " $\mathrm{x}$ is true-from-some-context" is descending true (whichever alethic standard is force) just in case there is an alethic standard that would render " $\mathrm{x}$ is true" descending true. This is spelt out thus:

(a) $\quad \mathrm{A}_{\langle\mathrm{w}, \mathrm{t},\rangle}([$ true-from-some-context(x)]) 


$$
\left[\mathrm{A}_{\langle\mathrm{w}, \mathrm{t}, \mathrm{SA}\rangle}\left(\left[\mathrm{A}_{\langle\mathrm{w}, \mathrm{t}, \mathrm{SA}\rangle}(\mathrm{x})\right]\right) \vee \mathrm{A}_{\langle\mathrm{w}, \mathrm{t}, \mathrm{SD}\rangle}\left(\left[\mathrm{D}_{\langle\mathrm{w}, \mathrm{t}, \mathrm{SD}\rangle}(\mathrm{x})\right]\right)\right]
$$

(b) $\quad \mathrm{D}_{\langle\mathrm{w}, \mathrm{t},\rangle}([$ true-from-some-context(x)])

$$
\left[\mathrm{D}_{\langle\mathrm{w}, \mathrm{t}, \mathrm{SA}\rangle}\left(\left[\mathrm{A}_{\langle\mathrm{w}, \mathrm{t}, \mathrm{SA}\rangle}(\mathrm{x})\right]\right) \quad \vee \quad \mathrm{D}_{\langle\mathrm{w}, \mathrm{t}, \mathrm{SD}\rangle}\left(\left[\mathrm{D}_{\langle\mathrm{w}, \mathrm{t}, \mathrm{SD}\rangle}(\mathrm{x})\right]\right)\right] .
$$

The predicate is not assessment-sensitive, and thus $(3 \mathrm{a}, \mathrm{b})$ hold whichever alethic standard is in force.

A liar-like sentence can be constructed using "true-from-some-context". Consider a sentence of our object language, which is denoted (in both the object language and metalanguage) by " $\lambda$ "':

Not: true-from-some-context $\left(\lambda^{\prime}\right)$.

We can derive the ascending and descending truth conditions for $\lambda^{\prime}$. From $\left(\mathrm{N}_{\mathrm{A}}\right)$ and $\left(\mathrm{N}_{\mathrm{D}}\right)$ we obtain:

(4) (a) $\quad \mathrm{A}_{\langle\mathrm{w}, \mathrm{t},\rangle}\left(\left[\right.\right.$ Not: true-from-some-context $\left.\left.\left(\lambda^{\prime}\right)\right]\right) \leftrightarrow \sim \mathrm{A}_{\langle\mathrm{w}, \mathrm{t},\rangle}\left(\left[\right.\right.$ true-from-some-context $\left.\left.\left(\lambda^{\prime}\right)\right]\right)$

(b) $\quad \mathrm{D}_{\langle\mathrm{w}, \mathrm{t},\rangle}\left(\left[\right.\right.$ Not: true-from-some-context $\left.\left.\left(\lambda^{\prime}\right)\right]\right) \leftrightarrow \sim \mathrm{D}_{\langle\mathrm{w}, \mathrm{t},\rangle}\left(\left[\right.\right.$ true-from-some-context $\left.\left.\left(\lambda^{\prime}\right)\right]\right)$

Then, using the relevant instances of $(3 a, b)$, we obtain:

(a) $\quad \mathrm{A}_{(\mathrm{w}, \mathrm{t},\rangle}\left(\left[\right.\right.$ Not: true-from-some-context $\left.\left.\left(\lambda^{\prime}\right)\right]\right) \leftrightarrow$

$$
\sim\left[\mathrm{A}_{\langle\mathrm{w}, \mathrm{t}, \mathrm{SA}\rangle}\left(\left[\mathrm{A}_{\langle\mathrm{w}, \mathrm{t}, \mathrm{SA}\rangle}\left(\lambda^{\prime}\right)\right]\right) \vee \mathrm{A}_{\langle\mathrm{w}, \mathrm{t}, \mathrm{SD}\rangle}\left(\left[\mathrm{D}_{\langle\mathrm{w}, \mathrm{t}, \mathrm{SD}\rangle}\left(\lambda^{\prime}\right)\right]\right)\right]
$$

(b) $\quad \mathrm{D}_{\langle\mathrm{w}, \mathrm{t},\rangle}\left(\left[\right.\right.$ Not: true-from-some-context $\left.\left.\left(\lambda^{\prime}\right)\right]\right) \leftrightarrow$

$$
\sim\left[\mathrm{D}_{\langle\mathrm{w}, \mathrm{t}, \mathrm{SA}\rangle}\left(\left[\mathrm{A}_{\langle\mathrm{w}, \mathrm{t}, \mathrm{SA}\rangle}\left(\lambda^{\prime}\right)\right]\right) \vee \mathrm{D}_{\langle\mathrm{w}, \mathrm{t}, \mathrm{SD}\rangle}\left(\left[\mathrm{D}_{\langle\mathrm{w}, \mathrm{tSD}\rangle}\left(\lambda^{\prime}\right)\right]\right)\right]
$$

Finally, using the fact that $\lambda^{\prime}=\left[\right.$ Not: true-from-some-context $\left.\left(\lambda^{\prime}\right)\right]$, and simplifying the right-hand sides of the biconditionals in (5), we obtain:
(a) $\quad \mathrm{A}_{\langle\mathrm{w}, \mathrm{t},\rangle}\left(\lambda^{\prime}\right) \leftrightarrow\left[\sim \mathrm{A}_{\langle\mathrm{w}, \mathrm{t}, \mathrm{SA}\rangle}\left(\left[\mathrm{A}_{\langle\mathrm{w}, \mathrm{t}, \mathrm{SA}\rangle}\left(\lambda^{\prime}\right)\right]\right) \wedge \sim \mathrm{A}_{\langle\mathrm{w}, \mathrm{t}, \mathrm{SD}\rangle}\left(\left[\mathrm{D}_{\langle\mathrm{w}, \mathrm{t}, \mathrm{SD}\rangle}\left(\lambda^{\prime}\right)\right]\right)\right]$
(b) $\quad \mathrm{D}_{\langle\mathrm{w}, \mathrm{t},\rangle}\left(\lambda^{\prime}\right) \leftrightarrow\left[\sim \mathrm{D}_{\langle\mathrm{w}, \mathrm{t}, \mathrm{SA}\rangle}\left(\left[\mathrm{A}_{\langle\mathrm{w}, \mathrm{t}, \mathrm{SA}\rangle}\left(\lambda^{\prime}\right)\right]\right) \wedge \sim \mathrm{D}_{\langle\mathrm{w}, \mathrm{t}, \mathrm{SD}\rangle}\left(\left[\mathrm{D}_{\langle\mathrm{w}, \mathrm{t}, \mathrm{SD}\rangle}\left(\lambda^{\prime}\right)\right]\right)\right]$. 
Fixing the world and time, we may now derive a contradiction. We first show that, from any context, $\lambda^{\prime}$ is neither ascending true nor descending true.

(i) $\quad \mathrm{A}_{\langle\mathrm{w}, \mathrm{t}, \mathrm{SA}\rangle}\left(\lambda^{\prime}\right)$

(ia) $\quad \sim \mathrm{A}_{\langle\mathrm{w}, \mathrm{t}, \mathrm{SA}\rangle}\left(\left[\mathrm{A}_{\langle\mathrm{w}, \mathrm{t}, \mathrm{SA}\rangle}\left(\lambda^{\prime}\right)\right]\right)$

(ib) $\quad \sim \mathrm{A}_{\langle\mathrm{w}, \mathrm{t}, \mathrm{SA}\rangle}\left(\lambda^{\prime}\right)$

(ii) $\quad \sim \mathrm{A}_{\langle\mathrm{w}, \mathrm{t}, \mathrm{SA}\rangle}\left(\lambda^{\prime}\right)$

(iii) $\quad \sim \mathrm{A}_{\langle\mathrm{w}, \mathrm{t},\rangle}\left(\lambda^{\prime}\right)$

(iv) $\quad \sim \mathrm{A}_{\langle\mathrm{w}, \mathrm{t,}\rangle}\left(\lambda^{\prime}\right) \wedge \sim \mathrm{D}_{\langle\mathrm{w}, \mathrm{t},\rangle}\left(\lambda^{\prime}\right)$

\section{(supposed for reductio)}

(by (i), $(6 a \rightarrow))$

(by (ia), (A), modus tollens)

(by (i)-(ib), reductio)

(by (ii), $\left.(6 a)^{13}\right)$

(by (iii), (S))

As w and $t$ are arbitrary and (iv) is independent of alethic standard, we can thus conclude:

(v) $\quad \forall \mathrm{w}, \mathrm{t}, \mathrm{s}: \sim \mathrm{A}_{\langle\mathrm{w}, \mathrm{t}, \mathrm{s}\rangle}\left(\lambda^{\prime}\right) \wedge \sim \mathrm{D}_{\langle\mathrm{w}, \mathrm{t}, \mathrm{s}\rangle}\left(\lambda^{\prime}\right)$.

We now fix an arbitrary alethic standard, s.

(vi) $\quad \sim \mathrm{A}_{\langle\mathrm{w}, \mathrm{t}, \mathrm{s}\rangle}\left(\lambda^{\prime}\right)$

(vii) $\quad \sim \mathrm{A}_{\langle\mathrm{w}, \mathrm{t}, \mathrm{s}\rangle}\left(\left[\right.\right.$ Not: true-from-some-context $\left.\left.\left(\lambda^{\prime}\right)\right]\right)$

(viii) $\quad \mathrm{D}_{\langle\mathrm{w}, \mathrm{ts}\rangle}\left(\left[\right.\right.$ true-from-some-context $\left.\left.\left(\lambda^{\prime}\right)\right]\right)$

(ix) $\quad \mathrm{D}_{\langle\mathrm{w}, \mathrm{t}, \mathrm{SA}\rangle}\left(\left[\mathrm{A}_{\langle\mathrm{w}, \mathrm{t}, \mathrm{SA}\rangle}\left(\lambda^{\prime}\right)\right]\right) \vee \mathrm{D}_{\langle\mathrm{w}, \mathrm{t}, \mathrm{SD}\rangle}\left(\left[\mathrm{D}_{\langle\mathrm{w}, \mathrm{t}, \mathrm{SD}\rangle}\left(\lambda^{\prime}\right)\right]\right)$

(x) $\quad \mathrm{A}_{\langle\mathrm{w}, \mathrm{t}, \mathrm{SA}\rangle}\left(\lambda^{\prime}\right) \quad \vee \quad \mathrm{D}_{\langle\mathrm{w}, \mathrm{t}, \mathrm{SD}\rangle}\left(\lambda^{\prime}\right)$ (by (iii))

(by (vi), expanding $\lambda^{\prime}$ )

(by (vii), $(\mathrm{M} \leftarrow)$ )

(by (viii), $(3 \mathrm{~b} \longrightarrow))$

(by (ix), (D), case analysis)

As w and t are arbitrary, we can (by existential generalisation and case analysis) conclude:

(xi) $\quad \exists \mathrm{w}, \mathrm{t}, \mathrm{s}: \mathrm{A}_{\langle\mathrm{w}, \mathrm{t}, \mathrm{s}\rangle}\left(\lambda^{\prime}\right) \vee \mathrm{D}_{\langle\mathrm{w}, \mathrm{t}, \mathrm{s}\rangle}\left(\lambda^{\prime}\right)$

\footnotetext{
${ }^{13}$ We use (6a) to infer (iii) by noting that (6a) encodes the insensitivity of $\lambda^{\prime}$ to alethic standard.
} 
The conjunction of $(\mathrm{v})$ and (xi) is a contradiction. Let " $\Gamma(\mathrm{x})$ " be the open formula $\left[\exists w, t, s: A_{\langle w, t, s}(\mathrm{x}) \vee\right.$ $\left.\mathrm{D}_{\langle\mathrm{w}, \mathrm{ts}\rangle}(\mathrm{x})\right]$. Then the conjunction of (v) and (xi) is equivalent to the contradiction:
$\left(\perp^{\prime}\right) \quad \sim \Gamma\left(\lambda^{\prime}\right) \wedge \Gamma\left(\lambda^{\prime}\right)$
(by (v) and (xi))

As such, Scharp's inconsistency approach faces a revenge problem.

\section{Objections and replies}

Objection. There is no predicate "true-from-some-context" in natural language, so Scharp's account works fine for natural languages as they stand.

Reply. There are two things to say about this. First, natural languages may be extendable: once "true-from-some-context" has been introduced, then plausibly it does appear to be expressible in natural language. Second, demonstratives and definite descriptions allow for a great deal of flexibility in what can be expressed in a natural language. For example, imagine pointing at $(3 a, b)$ and uttering “what I'm saying now doesn't fall under this". Scharp agrees: "seemingly innocent languages can harbor revenge paradoxes because they have the ability to refer indirectly to languages with explicit revenge paradoxes" (Scharp 2013a: 111).

Objection. Given the assessment-sensitive treatment of natural language, the predicate "truefrom-some-context" is illegitimate. If the extension of "true" is sensitive to a context of assessment, then one cannot build out of it a complex predicate that simply bypasses this feature. (Compare: one cannot use "I from Alice's perspective" to refer to Alice.)

Reply. It is important to see that "true-from-some-context" is not a complex predicate in this sense: it is not compositionally constructed from its hyphenated parts. The hyphenated parts merely serve to provide an intuitive idea of the intended meaning of the term. But the term is defined without reference to its parts in (3a,b), and none of the subsequent argument depends on those parts. 
(Compare: one could legitimately define "I-from-Alice's-perspective" as a (slightly awkward) singular term that refers to Alice.)

Objection. Scharp can respond by claiming that the concept of truth-from-some-context is inconsistent. He may say that, in using the concept to derive an inconsistency, I have not raised a revenge problem but merely succeeded in establishing that the concept of truth-from-some-context is inconsistent. He could in principle proceed to replace the concept and provide a relativistic treatment of my use of the predicate "true-from-some-context", which would (we may presume) highlight a fallacy in my argument.

Reply. I did not just use the concept of truth-from-some-context to derive the inconsistency. I also used Scharp's concepts of ascending truth, descending truth, alethic standard, context of assessment, etc. If one of the concepts involved in the derivation is to be deemed inconsistent, it does not immediately follow that it should be the concept of truth-from-some-context. Now, Scharp has a consistency proof for ADT (the prescriptive theory), so we might accept that the concepts of ascending and descending truth are consistent $;{ }^{14}$ but he provides no such consistency proof for the theory obtained by combining ADT with his assessment-sensitive semantic theory for "true" (the descriptive theory). As such, if Scharp intends to conclude that the concept of truth-from-somecontext is inconsistent, then it is incumbent upon him to at least provide an independent argument for the consistency of the concepts of alethic standard, context of assessment, etc. Difficulties would remain, however.

First, even if Scharp deems the concept of truth-from-some-context inconsistent, there would remain the threat of revenge. By analogy to the strategy in the present paper, for example, one could construct a "true-from-some-context-from-some-context" predicate. Scharp would presumably then deem the concept of truth-from-some-context-from-some-context inconsistent, but then another predicate could be constructed, etc. The worry is that we would lack a stable statement of Scharp's inconsistency approach that did not face revenge.

\footnotetext{
${ }^{14}$ See Scharp 2013a: 178-186.
} 
Second, deeming the concept of truth-from-some-context inconsistent may backfire. Although in $\S 3$ I introduced the predicate "true-from-some-context", such a predicate might not have been required to generate revenge. Perhaps I could have proceeded by consideration of a complex predicate, built up from a mixture of ordinary terms and Scharp's technical terms, such as: "is ascending-true while SA in force, or is descending-true while SD is in force". The reader is invited to compare the intuitive ascending and descending truth conditions of such a predicate against those given in $(3 a, b)$. If such a complex predicate can indeed be used to generate revenge, then it is difficult to see how Scharp could deem the underlying concept inconsistent without this filtering back to his own concepts of alethic standard (i.e. the concepts of SA and SD).

Third, I am not sure that it is even acceptable for Scharp to deem the concept of truth-fromsome-context inconsistent without also deeming the concept of alethic standard to be inconsistent. Concepts do not come independently, but in clusters. For example, the concept of North is essentially tied to the concepts of South, East, and West. For such a cluster, it would not make sense to say that only one of the concepts in that cluster is inconsistent: we should not deem the concept of East to be inconsistent while allowing the concepts of North, South and West to be consistent. Likewise, we could not remove the concepts of East from our conceptual scheme without also removing the concepts of North, South and West. Concepts in such a cluster stand and fall together.

The worry for Scharp is that the concept of alethic standard is in a cluster with the concept of truth-from-some-context. Here's a reason to think why. It appears to be the case that: one can genuinely grasp the idea of sentences being subject to different alethic standards that apply from different standpoints if, and only if, one can genuinely grasp the idea of there being a standpoint from which a given sentence meets the corresponding standard. This follows from the compositionality of thought, roughly as follows. ${ }^{15}$ First, one can genuinely grasp the thought that, for any $x, x$ can be in the extension of "true" only relative to an alethic standard if, and only if, one is competent with the constituents of that thought. Second, one is competent with the constituents of that thought if, and

\footnotetext{
${ }^{15}$ In the following argument, I assume that one has competence with the relevant grammatical constructions and that, for example, one has competence with universal quantification just in case one has competence with existential quantification.
} 
only if, one can genuinely grasp any other thought that contains only those constituents (and other concepts with which one is competent). Finally, one can do that if, and only if, one can genuinely grasp the thought that, for some $x$, there can be an alethic standard relative to which $x$ is in the extension of "true". That is, competence with Scharp's concept of alethic standard is sufficient for competence with the concept of truth-from-some-context, and vice versa.

If this is right, then Scharp's concept of alethic standard stands and falls with the concept of truth-from-some-context. If Scharp successfully argues that the concept of truth-from-some-context is inconsistent, then we should not just remove that concept from our conceptual scheme: we should also remove Scharp's concept of alethic standard.

\section{Concluding remarks}

Scharp's inconsistency approach has three central components: a diagnostic theory (that the concept of truth is inconsistent); a prescriptive theory (ADT); and a descriptive theory (an assessmentsensitive semantics for "true"). Using the resources afforded by the prescriptive and descriptive theories, I raised (in §3) a revenge problem facing Scharp’s inconsistency approach. In light of an objection (discussed in §4), Scharp may be able to localise the problem to his descriptive theory.

Even if the revenge problem can be so localised, it is nonetheless important. What was so exciting about Scharp's inconsistency approach was that it purported to not even face a revenge problem. As such, it is significant that the approach does face a revenge problem, even if that problem can subsequently be localised.

Moreover, Scharp characterises the descriptive theory as a theory "of our inconsistent concept of truth" (2013b: 461), emphasising "that [it] is the centerpiece of an inconsistency approach to the aletheic paradoxes" (p. 432) and implicitly endorsing the view that it is "the most essential element in an approach to the aletheic paradoxes" (ibid.). The descriptive theory is central, at least in part, because, by assigning extensions to "true", it provides an account of which steps in the derivation of the liar paradox are fallacious. And such an account, so goes the thought, is a key element to any approach to the paradox — key, because it has proved so difficult to provide a plausible, systematic 
account of the fallacious steps without incurring revenge. Scharp's descriptive theory, then, is central to his inconsistency approach. However, if I am right, the descriptive theory suffers in the same way as previous attempts to highlight the fallacious steps in the derivation of the liar paradox.

Perhaps Scharp will seek to construct an alternative descriptive theory. The idea would presumably be to provide an alternative interpretation of "true" that, in part, highlights some steps in the derivation of the liar paradox as fallacious and does not face revenge. But there are two points of caution to note. First, we already know that, in general, such an aim is very difficult to satisfy. And, second, the result herein suggests that Scharp's underlying strategy—removing and replacing the source of the paradoxes - has not obviously improved the chance of success. It remains unclear whether revenge problems can be avoided, with or without the concept of truth. ${ }^{16}$

\section{References}

Beall, J.C. 2007. Prolegomenon to future revenge. In Beall, J.C. (ed.) Revenge of the Liar: New Essays on the Paradox: 1-30. Oxford: Oxford University Press.

Kripke, S. 1975. Outline of a theory of truth. Journal of Philosophy 72(19): 690-716.

Scharp, K. 2013a. Replacing Truth. Oxford: Oxford University Press.

—. 2013b. Truth, the liar, and relativism. Philosophical Review 122(3): 427-510.

—. 2014. Truth, revenge, and internalizability. Erkenntnis 79 (Issue 3 Supplement): 597-645.

Shapiro, L. 2011. Expressibility and the liar's revenge. Australasian Journal of Philosophy 89(2): $297-314$.

\footnotetext{
${ }^{16}$ Thanks to Anthony Everett, Kevin Scharp and an anonymous referee for helpful comments and feedback.
} 